\title{
An experimental study on the shear behaviour of reinforced concrete beams with macro-synthetic fibres
}

\author{
F. Ortiz Navas ${ }^{\text {a,* }}$, Juan Navarro-Gregori ${ }^{\text {a }}$, G. Leiva Herdocia ${ }^{\text {a }}$, P. Serna ${ }^{\text {a }}$, E. Cuenca ${ }^{\text {b }}$ \\ ${ }^{a}$ Instituto de Ciencia y Tecnología del Hormigón (ICITECH), Universitat Politècnica de València, Camino de Vera s/n, 46022 Valencia, Spain \\ ${ }^{\mathrm{b}}$ Department of Civil and Environmental Engineering - DICA. Politecnico di Milano Piazza Leonardo da Vinci 32, 20133 Milan, Italy
}

\begin{abstract}
A B S T R A C T
Shear behaviour in reinforced concrete (RC) elements can improve with an adequate amount of fibres. Research has recently determined how fibres affect shear strength, but has barely focused on macro-synthetic fibre-reinforced concrete (PFRC). This paper presents the experimental results of 16 full-scale beams (eight RC, eight PFRC), 12 without transverse reinforcement. Polypropylene fibres $\left(10 \mathrm{~kg} / \mathrm{m}^{3}\right)$ were included. Mode of failure (MOF) in shear and behaviour throughout the loading process were studied. The results obtained with fibres showed significantly improved shear strength in the RC beams with/without transverse reinforcement. A synergy between transverse reinforcement and fibres was observed in some cases.
\end{abstract}

\section{Introduction}

The shear behaviour of structural concrete elements is a research topic that is being continuously debated by researchers. Shear behaviour is influenced mainly by: effective depth (d), compressive concrete strength, the longitudinal reinforcement ratio, coarse aggregate size, the presence or absence of prestressing, load conditions, and the shear span/depth ratio (a/d). Bresler-Scordelis [1], tested 12 reinforced concrete (RC) beams in 1963 at the University of Berkeley in order to investigate critical shear behaviour. This beams series covered a wide range of transversal reinforcement and span conditions. The shear research community has considered this classical beam series to be a reference for calibrating numerical models. At the University of Toronto, VecchioShim [2] reproduced classical Bresler-Scordelis beams in 2004 to test the repeatability of the results obtained by Bresler, particularly for load capacity and mode of failure (MOF).

\footnotetext{
* Corresponding author.

E-mail address: fraorna@doctor.upv.es (F. Ortiz Navas).
}

Research into shear has also been applied by some authors to fibre-reinforced concrete (FRC) structural elements, in which the most important variables were: amount [3], shape, material and slenderness (aspect ratio, $1 / d$ ) of fibres [4,5], as well as the presence [6,7] or absence [8-15] of stirrups, or the combination of stirrups and fibres [7,16,17].

Design guidelines have recently allowed fibres to be used as shear reinforcement; e.g., Model Code 2010 [18] and the ACI Building Code [19]. In particular, Model Code 2010 [18] provides two different formulations to properly evaluate the shear strength of FRC elements. The ACI Building Code [19] allows steel fibres to be used in volume fractions that exceed or equal $0.75 \%$ as a mini-mum shear reinforcement in normal-strength concrete beams.

According to the experimental results, it is well-known that steel fibres are used to enhance concrete shear capacity and postcracking tensile strength since FRC is characterised by enhanced toughness due to the bridging effects provided by steel fibres $[20,21]$. Steel fibres also provide substantial post-peak resistance and ductility [11,20,22], and can transform brittle MOF into ductile ones [22-26]. Cuenca and Serna [16] also proved the 


\section{Notation}

a shear span

$A_{S} \quad$ longitudinal reinforcement area

$A_{\text {sw }} \quad$ transversal reinforcement area

b beam width

CMOD crack mouth opening displacement

d effective depth

$\mathrm{E}_{\mathrm{c}} \quad$ modulus of elasticity of concrete

$\mathrm{f}_{\mathrm{ck}} \quad$ characteristic value of compressive strength of concrete

$\mathrm{f}_{\mathrm{cm}} \quad$ mean value of compressive strength of concrete

$\mathrm{f}_{\mathrm{ctm}} \quad$ mean tension strength of concrete

$\mathrm{f}_{\mathrm{ctk}} \quad$ characteristic value of tensile strength of concrete $\mathrm{w} / \mathrm{o}$ fibres

$\mathrm{f}_{\mathrm{L}} \quad$ limit of proportionality

$\mathrm{f}_{\mathrm{Rj}} \quad$ residual flexural tensile strength corresponding to CMDO 1-4

$\mathrm{f}_{\mathrm{Rjk}} \quad$ residual flexural tensile characteristic strengths corresponding to CMDO 1-4

$\mathrm{f}_{\mathrm{u}} \quad$ value of the ultimate strength of reinforcement

$\mathrm{f}_{\mathrm{y}} \quad$ value of the yield strength of reinforcement h beam depth

L beam length

$\mathrm{P}_{\mathrm{u}} \quad$ peak load

$\mathrm{S}$ distance between transverse reinforcements

$v_{u} \quad$ nominal shear strength

$\mathrm{V}_{\mathrm{f}} \quad$ fibre volume fraction

$\mathrm{V}_{\mathrm{u}} \quad$ shear force on the considered section

$v_{c} \quad$ contribution of concrete to shear strength

$v_{s} \quad$ contribution of steel to shear strength

$v_{f} \quad$ contribution of fibre to shear strength

$\mathrm{w}_{\mathrm{f}} \quad$ flexural crack width

$\mathrm{w}_{\mathrm{s}} \quad$ shear crack width

$\mathrm{z} \quad$ internal lever arm

ou deflection at peak load

$\varepsilon_{\mathrm{c}} \quad$ longitudinal strain measured in the compression zone

$\varepsilon_{t} \quad$ longitudinal strain measured at longitudinal reinforcement

$\rho_{s} \quad$ longitudinal reinforcement ratio

$\rho_{\mathrm{w}} \quad$ transverse reinforcement ratio beneficial effect of steel fibres as shear reinforcement in prestressed elements in self-compacting concrete. Presence of steel fibres alone, or combined with conventional reinforcement, has led to enhanced shear strength and specimens ductility. In this study, no clear differences according to the post-peak behaviour between the prestressed beams reinforced only with stirrups or those reinforced only with steel fibres were observed.

The use of steel fibres can also offer a clear advantage in structural elements where it is difficult, or even impossible, to place transverse reinforcements, such as hollow core slabs [27].

To date, the vast majority of the research conducted on the shear behaviour of FRC has focused on steel fibres [5,16,27-34] as very few studies on macro-synthetic fibres are found in the lit-erature, such as $[7,9,10,35,36]$. Macro-synthetic fibres have signif-icantly improved in the past decade, and can now be used in structural applications, as long as fibre long-term behaviour is guaranteed $[37,38]$. In fact macro-synthetic fibres are currently able to fulfil the Model Code 2010 requirement [4] for structural applications, and experimental studies have shown their suitability as shear reinforcement in beams [7,9,10,39], prestressed double tees [40], flat suspended slabs [41] and as a reinforcement in precast tunnel segments [42-44]. Regarding shear reinforcement, Altoubat et al. [9] tested 17 full-scale beams without (w/o) stir-rups, but with straight macro-synthetic fibres. Compared to the reference samples, the increment in shear strength with a volume fraction of fibres, which varied from 0.5 to $1.0 \%$, fell within the $14-30 \%$ range. Based on two experimental programmes on 14 wide-shallow beams and 19 deep beams reinforced by polypropy-lene fibres, Conforti et al. [7] showed that macro-synthetic fibres can be used as a shear reinforcement in these structural elements. Similar results have also been obtained by Sahoo et al. [10]. Guray et al. [36] studied the influence of polypropylene fibres on the shear behaviour on 11 beams w/o transversal reinforcement by varying the shear span-effective depth ratio from 2.5 to 4.5 , and the volume fraction of fibres. Their tests showed that strength and ductility had improved by adding synthetic fibres and, in certain cases, the MOF has changed depending on the shear span-depth and the volume fraction of fibres.

Even though these studies can certainly be considered to represent the good progress made in knowledge about the shear behaviour of elements reinforced by macro-synthetic fibres, a limited number of experimental results, and only a few factors that affect shear strength, have been studied in the presence of macrosynthetic fibres.

\section{Research significance}

The shear behaviour of steel fibre-reinforced concrete (SFRC) has been more extensively investigated than macro-synthetic fibrereinforced concrete (PFRC). In the last few years, several authors have organised experimental campaigns to determine the shear contribution provided by synthetic fibres in slender beams w/o transverse reinforcement. The objective of the present paper is to determine firstly the benefits of macro-synthetic polypropylene fibres used as a shear reinforcement in structural slender beams both with and w/o transversal reinforcement (stir-rups), and secondly the synergy that exists between fibres and stir-rups when both are used together as a transversal reinforcement. For this propose, the classic test beams series by Bresler and Scordelis in 1963 [1] was reproduced, and a new series of beams was incorporated to cover a wide range of reinforcement and span conditions and, hence, a range of influencing factors and MOFs.

\section{Experimental programme}

\subsection{Test specimens}

The research by Bresler-Scordelis [1] consisted of 12 beams (four series of three beams) with a different cross-section geometry, an amount of longitudinal reinforcement, transverse reinforcement, span length and concrete compressive strength. Most beams, except those of maximum length, failed by shear, specifically due to diagonal tension (D-T) or shear-compression (V-C). The ICITECH beams are somewhat inspired by these two classic series of reinforced concrete beams. In fact the reproduced beams are A1 $(305 \times 552 \times 3660 \mathrm{~mm})$, A2 $(305 \times 552 \times 4570 \mathrm{~mm})$, B1 $(229 \times$ $552 \times 3660 \mathrm{~mm})$, B2 $(229 \times 552 \times 4570 \mathrm{~mm})$, OA1 (A1 w/o stirrups) and OA2 (A2 w/o stirrups). Those beams with a span length of $6400 \mathrm{~mm}$, "Series 3", and with a failing flexure-compression (F-C), were excluded from the experimental programme, as were the " $\mathrm{C}$ " series beams with a cross-section of $155 \times 552 \mathrm{~mm}$. Two new beams were added: OB1 (B1 w/o stirrups) and OB2 (B2 w/o stirrups). Thus the whole series of RC beams consists in eight beams, as shown in Fig. 1 and Table 1. 
Since the main objective of this research was to study shearcritical fibre-reinforced concrete beams, the experimental programme was extended to the specimens that contained PFRC. The series of PFRC beams had the same geometry as the series of RC beams. The details that correspond to the whole programme of 16 beams are summarised in Table 1 . This results in an interest-ing combination of parameters: (a) two different cross-sections ('A' 305 $\times 552 \mathrm{~mm}$ and ' $\mathrm{B}$ ' $229 \times 552 \mathrm{~mm}$ ); (b) two span lengths (' 1 ' 3360 mm and '2' $4570 \mathrm{~mm}$ ); (c) two concrete types: RC and PFRC; (d) repetitions with and w/o transverse reinforcement. It is noteworthy that symbol ' 0 ' was added to the specimen designation in the beams w/o transverse reinforcement, as was ' $\mathrm{P}$ ' in the macrosynthetic polypropylene FRC beams. The 16 above-described ICITECH beams formed part of an experimental campaign of 24 beams, in which the effect of SFRC was also studied [45].

Longitudinal and transverse reinforcements with similar properties to the traditional beams developed by Bresler et al. were chosen [1]. A large amount of longitudinal reinforcement was used to prevent flexure failure in bending. Steel longitudinal reinforcing bars of diameters of $25 \mathrm{~mm}$ and $20 \mathrm{~mm}$ were used as the bottom reinforcement. The amount of longitudinal reinforcement was $1.43 \%$ to $1.91 \%$, depending on the beam series. Bars of diameters of $12 \mathrm{~mm}$ and $10 \mathrm{~mm}$ were chosen as the longitudinal top reinforcement, and 8-mm stirrups anchored with $135^{\circ}$ bends were used as the transverse reinforcement. In order to prevent either bond failure or the influence of bond failure on other failure mechanisms, length of beams was extended $700 \mathrm{~mm}$ away from the supports in order to ensure sufficient anchorage, as shown in Fig. 2. Steel-end plates, like those in the Bresler-Scordelis [1] or VecchioShim[2] beams, were not used.

\subsection{Material properties}

Portland cement, two types of crushed limestone gravel, three kinds of fine aggregate, water and superplasticiser were used to prepare the concrete. Table 2 lists the dose that was taken into account in the 12 prepared mixtures. Maximum aggregate size was $20 \mathrm{~mm}$. The employed cement type was CEM I $42.5 \mathrm{~N}$. The water/cement $(\mathrm{w} / \mathrm{c})$ ratio was 0.50 . To obtain the desired high workability, superplasticiser was dosed in the order of $1 \%-1.1 \%$ (percentage of cement weight) in the RC mix, and of $1.4 \%-1.5 \%$ (percentage of cement weight) in the PFRC mix. The slump flow test was $612 \mathrm{~mm}$ on average, according to EN 12350-8:2011. The mix design for RC and PFRC was carried out for a characteristic compressive concrete strength of $35 \mathrm{MPa}$.

Polypropylene fibres, $48 \mathrm{~mm}$ long with a nominal aspect ratio (length/diameter) equal to 57, were used in the PFRC beams. Fig. 3 shows the geometry of the polypropylene fibres used in the experiments. Table 3 indicates the mechanical and physical properties of the macro-synthetic fibres employed in the test. Tensile strength and modulus of elasticity were $400 \mathrm{MPa}$ and $4.0 \mathrm{GPa}$ respectively, according to EN-ISO 6892-1-2009. The RC and PFRC beams were made in a concrete batching plant. Fibres were gradually incorporated into the mixture to not only ensure that fibres were correctly dispersed in the concrete, but to also guarantee the desired workability. Steel formworks were filled with several concrete batches (see Fig. 4) Twelve concrete batches were needed to fill the 16 beams.

In order to determine the mechanical properties of RC and PFRC, samples of concrete from each batch were used to obtain 48 cylindrical specimens of $150 \times 300 \mathrm{~mm}$ and 24 prismatic $(150 \times 150 \times$ $600 \mathrm{~mm}$ ) beam specimens. Both specimens and beams were cured at room temperature under similar conditions.

Cylinder specimens were used to determine both the concrete compressive strength and the modulus of elasticity of the concrete mixture. Uniaxial compression tests were carried out according to EN 12390-3. Increased loading was applied at a rate of $0.6 \mathrm{MPa} / \mathrm{s}$. Four cylinder specimens were tested per cast type. Modulus of elasticity was determined according to EN 12390-13 (see Fig. 6-a). The mean concrete compression strength $\left(\mathrm{f}_{\mathrm{cm}}\right)$ of all the exper-imental tests resulted in $42.17 \mathrm{MPa}$, with a coefficient of variation (CV) of $5.04 \%$. The concrete characteristic compression strength $\left(\mathrm{f}_{\mathrm{ck}}\right)$ was 38.30 $\mathrm{MPa}$, calculated with a reliability factor value $(\mathrm{K})$ of $1.80 . \mathrm{f}_{\mathrm{ck}}$ came close to the desired concrete compression strength of $35 \mathrm{MPa}$.
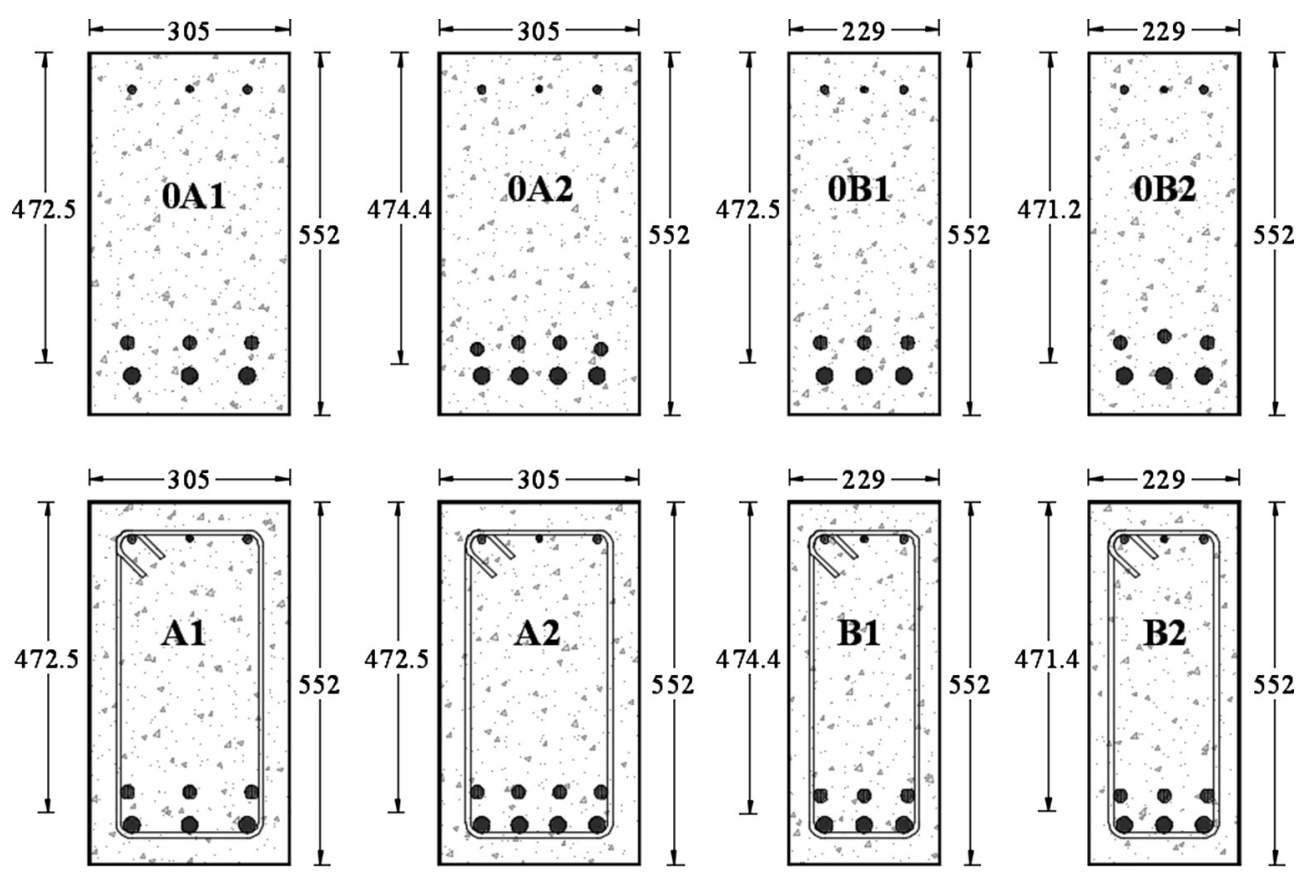

(UNITS IN MILLIMETERS)

Fig. 1. Cross-section details of the ICITECH Beams. 
Table 1

Cross-section details of the ICITECH Beams.

\begin{tabular}{|c|c|c|c|c|c|c|c|c|c|c|}
\hline Beam & $\mathrm{b}(\mathrm{mm})$ & $\mathrm{h}(\mathrm{mm})$ & $\mathrm{d}(\mathrm{mm})$ & $\mathrm{L}(\mathrm{mm})$ & Span $(\mathrm{mm})$ & $a / d$ & Bottom Steel (Ratio) ${ }^{1}$ & Top Steel (Ratio) ${ }^{1}$ & Stirrups (Ratio) $)^{2}$ & Fibres $\left(\mathrm{kg} / \mathrm{m}^{3}\right)$ \\
\hline OA1 & 305 & 552 & 472.5 & 5060 & 3660 & 3.87 & $3 \Phi 20+3 \Phi 25$ (1.68\%) & $2 \Phi 12+1 \Phi 10(0.21 \%)$ & - & - \\
\hline $\mathrm{OA} 2$ & 305 & 552 & 474.4 & 5970 & 4570 & 4.82 & $4 \Phi 20+4 \Phi 25(2.23 \%)$ & $2 \Phi 12+1 \Phi 10(0.21 \%)$ & - & - \\
\hline OB1 & 229 & 552 & 472.5 & 5060 & 3660 & 3.87 & $3 \Phi 20+3 \Phi 25$ (2.23\%) & $2 \Phi 12+1 \Phi 10(0.28 \%)$ & - & - \\
\hline OB2 & 229 & 552 & 471.2 & 5970 & 4570 & 4.85 & $3 \Phi 20+3 \Phi 25(2.24 \%)$ & $2 \Phi 12+1 \Phi 10(0.28 \%)$ & - & - \\
\hline $\mathrm{A} 1$ & 305 & 552 & 472.5 & 5060 & 3660 & 3.87 & $3 \Phi 20+3 \Phi 25$ (1.68\%) & $2 \Phi 12+1 \Phi 10(0.21 \%)$ & $\Phi 8$ at $330 \mathrm{~mm}(0.10 \%)$ & - \\
\hline $\mathrm{A} 2$ & 305 & 552 & 472.5 & 5970 & 4570 & 4.84 & $4 \Phi 20+4 \Phi 25$ (2.23\%) & $2 \Phi 12+1 \Phi 10(0.21 \%)$ & $\Phi 8$ at $330 \mathrm{~mm}(0.10 \%)$ & - \\
\hline B1 & 229 & 552 & 474.4 & 5060 & 3660 & 3.86 & $3 \Phi 20+3 \Phi 25(2.22 \%)$ & $2 \Phi 12+1 \Phi 10(0.28 \%)$ & $\Phi 8$ at $300 \mathrm{~mm}(0.15 \%)$ & - \\
\hline B2 & 229 & 552 & 474.4 & 5970 & 4570 & 4.82 & $3 \Phi 20+3 \Phi 25(2.22 \%)$ & $2 \Phi 12+1 \Phi 10(0.28 \%)$ & $\Phi 8$ at $300 \mathrm{~mm}(0.15 \%)$ & - \\
\hline OAP1 & 305 & 552 & 472.9 & 5060 & 3660 & 3.87 & $3 \Phi 20+3 \Phi 25$ (1.67\%) & $2 \Phi 12+1 \Phi 10(0.21 \%)$ & - & 10 \\
\hline OAP2 & 305 & 552 & 472.5 & 5970 & 4570 & 4.84 & $4 \Phi 20+4 \Phi 25(2.23 \%)$ & $2 \Phi 12+1 \Phi 10(0.21 \%)$ & - & 10 \\
\hline OBP1 & 229 & 552 & 470.6 & 5060 & 3660 & 3.89 & $3 \Phi 20+3 \Phi 25$ (2.24\%) & $2 \Phi 12+1 \Phi 10(0.28 \%)$ & - & 10 \\
\hline OB2 & 229 & 552 & 469.2 & 5970 & 4570 & 4.87 & $3 \Phi 20+3 \Phi 25(2.25 \%)$ & $2 \Phi 12+1 \Phi 10(0.28 \%)$ & - & 10 \\
\hline AP1 & 305 & 552 & 475.0 & 5060 & 3660 & 3.85 & $3 \Phi 20+3 \Phi 25$ (1.67\%) & $2 \Phi 12+1 \Phi 10(0.21 \%)$ & $\Phi 8$ at $330 \mathrm{~mm}(0.10 \%)$ & 10 \\
\hline AP2 & 305 & 552 & 474.4 & 5970 & 4570 & 4.82 & $4 \Phi 20+4 \Phi 25$ (2.23\%) & $2 \Phi 12+1 \Phi 10(0.21 \%)$ & $\Phi 8$ at $330 \mathrm{~mm}(0.10 \%)$ & 10 \\
\hline BP1 & 229 & 552 & 481.0 & 5060 & 3660 & 3.80 & $3 \Phi 20+3 \Phi 25$ (2.19\%) & $2 \Phi 12+1 \Phi 10(0.28 \%)$ & $\Phi 8$ at $300 \mathrm{~mm}(0.15 \%)$ & 10 \\
\hline BP2 & 229 & 552 & 474.6 & 5970 & 4570 & 4.81 & $3 \Phi 20+3 \Phi 25(2.22 \%)$ & $2 \Phi 12+1 \Phi 10(0.28 \%)$ & $\Phi 8$ at $300 \mathrm{~mm}(0.15 \%)$ & 10 \\
\hline
\end{tabular}

${ }^{1}$ longitudinal reinforcement ratio in brackets. $\rho s=\frac{A_{s}}{b * d}$ as a percentage.

2 Transversal reinforcement ratio in brackets. $\rho w=\frac{A_{s w}}{b * s}$ as a percentage.

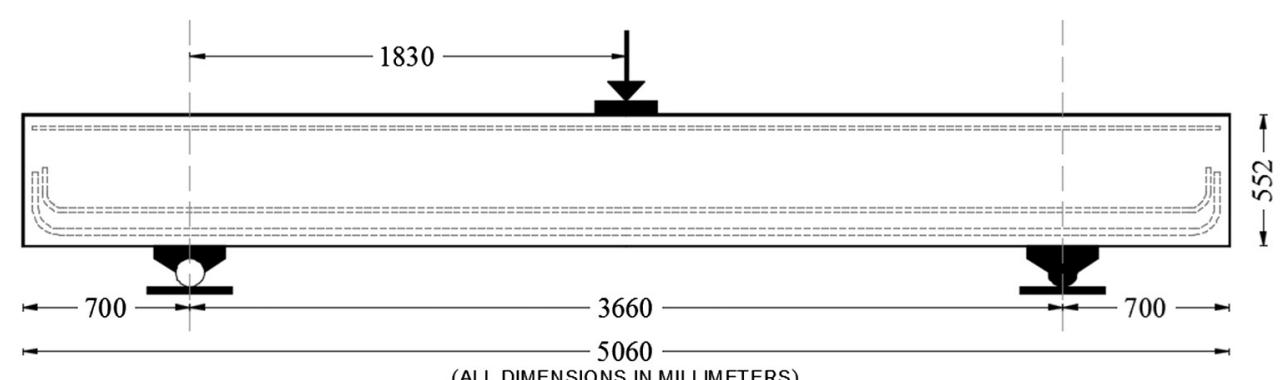

(ALL DIMENSIONS IN MILLIMETERS)

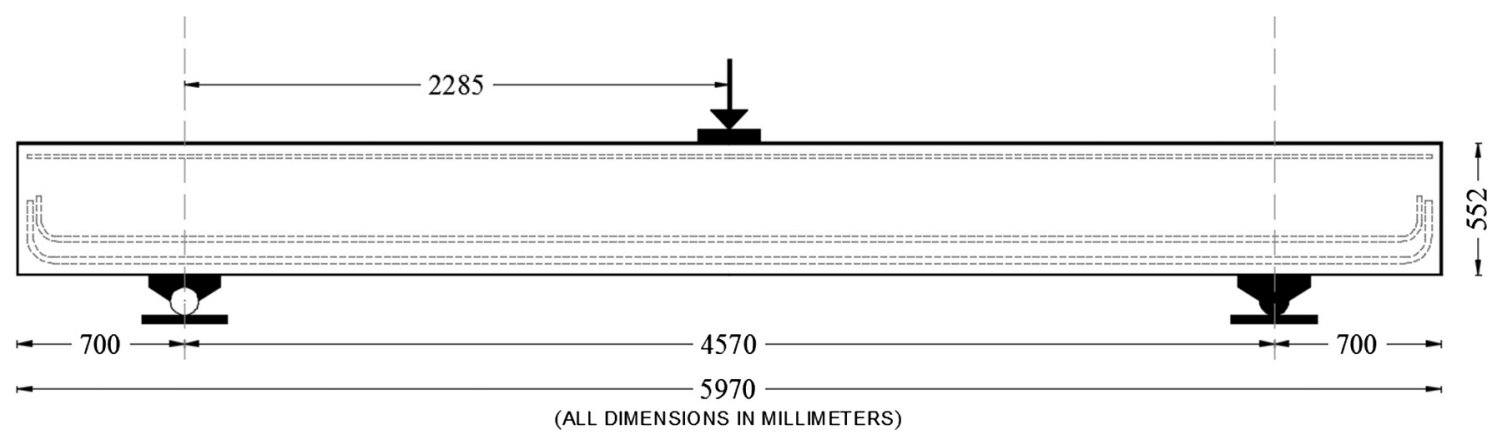

Fig. 2. Elevation details of the ICITECH Beams.

Table 2

Concrete doses considered $\left(\mathrm{kg} / \mathrm{m}^{3}\right)$.

\begin{tabular}{ll}
\hline Materials & Mix proportions $\left(\mathrm{kg} / \mathrm{m}^{3}\right)$ \\
\hline Crushed sand type 1 & 482 \\
Crushed sand type 2 & 168 \\
Crushed sand type 3 & 482 \\
Gravel 6/12 mm & 591 \\
Gravel 12/20 mm & 118 \\
Cement CEM I 42.5 N & 350 \\
Polypropylene fibres & $0(\mathrm{RC}) 10\left(\mathrm{~V}_{\mathrm{f}}=1.1 \%\right)(\mathrm{PFRC})$ \\
Water & 175 \\
Superplasticiser & $3.5-5.25$ \\
\hline
\end{tabular}

The residual tensile strengths of PFRC were tested according to EN 14651 (see Fig. 6-b). Three point-bending test setups were chosen. Load was applied at a rate of $0.05 \mathrm{~mm} / \mathrm{min}$ until $\mathrm{CMOD}=0.1$. After $C M O D=0.1$, the rate was gradually increased to $0.20 \mathrm{~mm} /$ min. It is worth mentioning that after the test, the number of fibres that bridged the crack was determined by visual counts to obtain a truer approximation of PFRC behaviour. Table 4 summarises the number of fibres per square decimetre and the other mean mechanical concrete properties per beam. Fig. 5 presents the graphics of the mean residual tensile strength of PFRC. The mean PFRC residual tensile strengths of all the experimental tests were $2.76 \mathrm{MPa}(15.83 \% \mathrm{CV})$ and $4.34 \mathrm{MPa}(18.16 \% \mathrm{CV})$ for $\mathrm{f}_{\mathrm{R} 1}$ and $\mathrm{f}_{\mathrm{R} 3}$, respectively. The PFRC residual characteristic tensile strengths, after taking account a $\mathrm{K}$ value of 1.29 , were $2.19 \mathrm{MPa}$, and $3.32 \mathrm{MPa}$ for $f_{R 1 k}$ and $f_{R 3 k}$, respectively. The material post-cracking strength of PFRC was classified as 2e according to Model Code 2010 [18].

Steel reinforcement samples were taken to determine tensile properties. Tensile tests were carried out according to EN-ISO 6892-1 (see Fig. 6-c), and the results are shown in Table 5. 


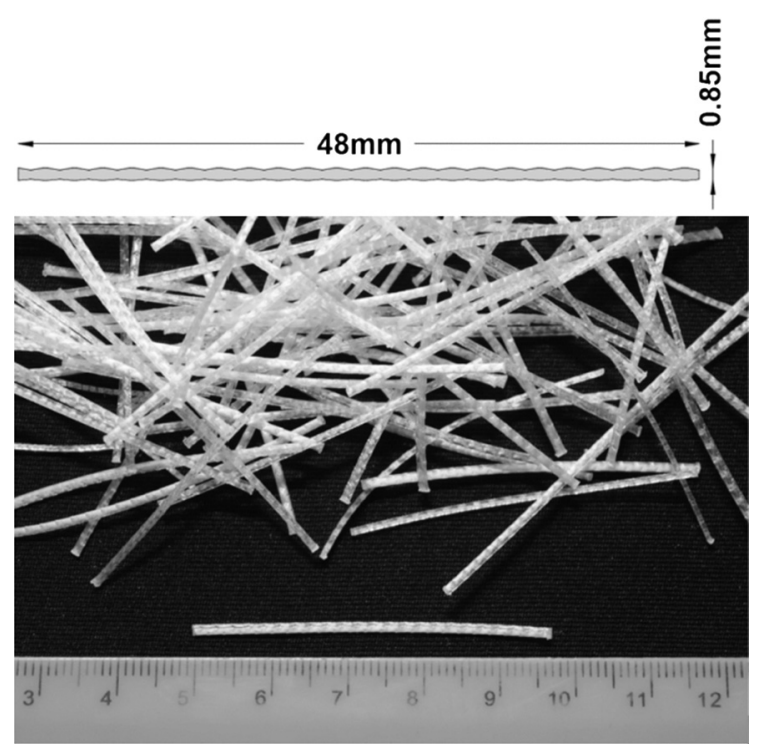

Fig. 3. Polypropylene macro-synthetic fibres.

Table 3

Mechanical and physical properties of the macro-synthetic fibre.

\begin{tabular}{ll}
\hline Properties & Value \\
\hline Material & Polyolefin $100 \%$ \\
Design & Monofilament \\
Equivalent diameter & $0.85 \mathrm{~mm}$ \\
Length & $48 \mathrm{~mm}$ \\
Tensile strength & $400 \mathrm{MPa}$ \\
Modulus of Elasticity & $4.7 \mathrm{GPa}$ \\
Water Absorption & Nil \\
Density & $0.91 \mathrm{~g} / \mathrm{cm}^{3}$ \\
Shape & Elliptical \\
Melting point & $160{ }^{\circ} \mathrm{C}$ \\
Ignition point & $350{ }^{\circ} \mathrm{C}$ \\
\hline
\end{tabular}

\subsection{Beams test setup}

The test setup to perform the experiments is shown in Fig. 7. A servo-hydraulic jack of $1000 \mathrm{kN}$ was used, which was connected to a universal testing machine. The test was carried out under the displacement control conditions of deflection at mid-span. Load was applied to all the beams at an average constant deflection rate of $0.30 \pm 0.10 \mathrm{~mm} / \mathrm{min}$.

In order to measure displacements, nine potentiometric displacement transducers (SDLs) were used as shown in Fig. 7. One was uti- lised for measuring deflection at mid-span and two as supports for capturing undesired vertical movements. Two horizontal devices were located at mid-span to measure the average strain in the compression and tension chords. Another set of two potentiometric displacement transducers was placed with some inclination on the shear span to record the diagonal cracking induced by shear (see Fig. 8-a). Finally, two other devices were placed at the top of the specimen, between the loading application point and the supports. In order to allow the horizontal displacements of beam due to bending and shearing deformations, one of the used supports was a roller sup-port (see Fig. 9), while the other was a pinned support.

Four high-resolution digital cameras were employed to take pictures of the beams every $10 \mathrm{~s}$ during the loading process, and a video camera recorded all the specimen failures (see Fig. 8-b). These digital devices are used to study crack propagation and to measure crack openings. A $100 \times 100 \mathrm{~mm}$ grid was painted on one of the lateral faces of the beam to facilitate further digital image correlations.

\section{Test results and observation}

This paper presents the state of the beams upon failure and at maximum load. Table 6 lists all 16 beams, experimental peak load $\mathrm{P}_{\mathrm{u}}$, peak experimental shear capacity, including self-weight $\mathrm{V}_{\mathrm{u}}$, shear strengths $v_{u}$, mid-span deflection $\delta_{\mathrm{u}}$ when the beam reaches $\mathrm{P}_{\mathrm{u}}$, the mid-span deformation at the top $\left(\varepsilon_{\mathrm{c}}\right)$ and bottom $\left(\varepsilon_{\mathrm{t}}\right)$ of the section, shear crack width $\left(\mathrm{w}_{\mathrm{s}}\right)$ and flexural crack width $\left(\mathrm{w}_{\mathrm{f}}\right)$ upon peak load. Shear capacity was determined as half the resisted maximum load and self-weight of each beam, calculated at a distance equal to the effective depth (d) from the bearing plate edge. Midspan deflection was corrected using the vertical reading obtained with the LVDTs placed on the bearing plates (see Fig. 7). The tensile and compression deformation at the mid-span were obtained with LVDTs 7 and 6, respectively (see Fig. 7). Three well-known and accepted MOFs in slender beams were addressed: Diagonal - tension (D-T), which is a brittle failure that takes place in slender beams with no or very little shear reinforcement; the Shear - compression $(V-C)$ MOF presents many inclined cracks, which grow and reduce the compression zone, with the beam failing at the end by splitting in the compression zone; The Flexure-compression ( $F-C$ ) MOF, which is a ductile failure that occurs when flexural cracks progress until they reach the compression zone and concrete starts crushing after yielding the longitudinal reinforcement.

Fig. 10 shows the load-deflection response for all the tested beams. For simplicity sake, the results are organised in four graphs, and each corresponds to the same cross-section (A or B) and the same span length ( 1 or 2 ). This makes it easier to study the effect of fibres and transverse reinforcement on shear behaviour in each case.

Since many photographs were taken of each specimen, it was possible to study the crack pattern evolution during the loading

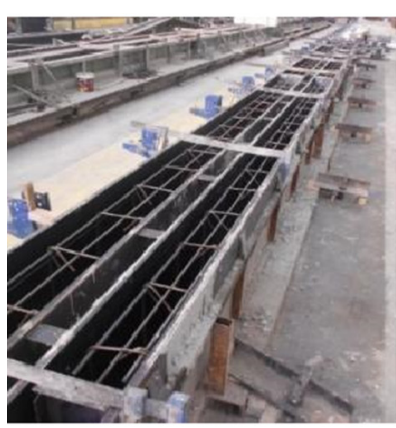

a)

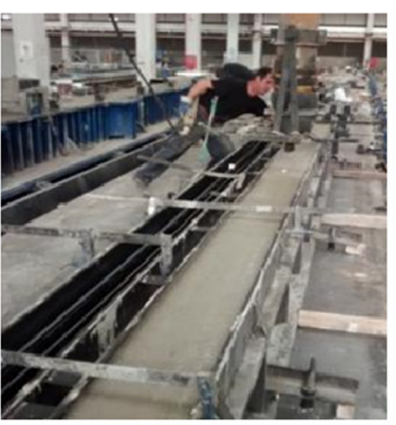

b)

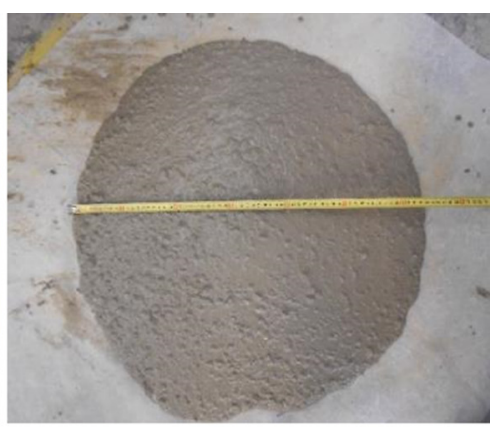

c)

Fig. 4. a) Formworks, b) Full casted beam, c) Slump Flow test. 


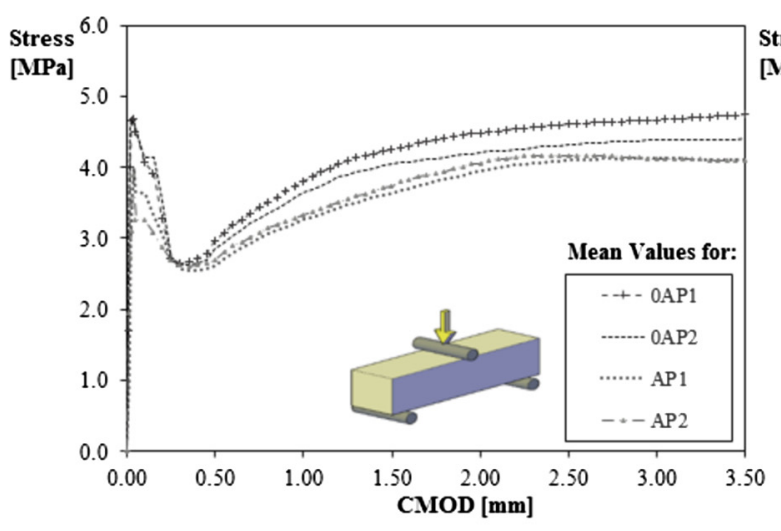

a)

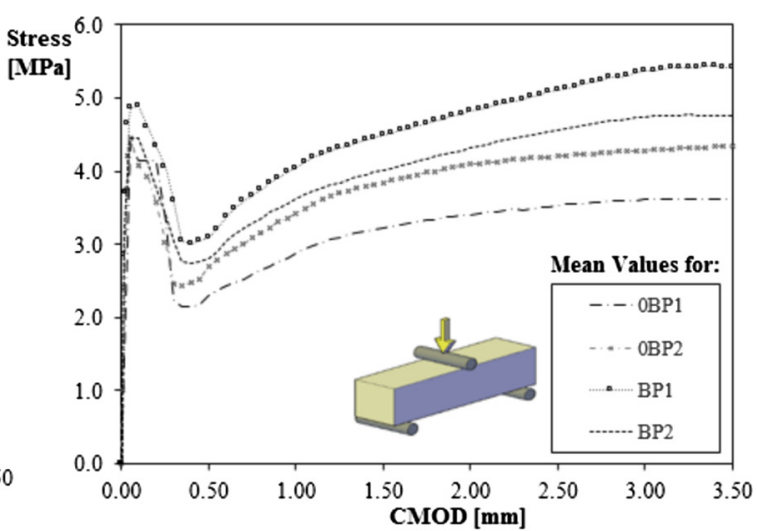

b)

Fig. 5. a) Series A, b) Series B, Beam Average Residual Tensile Strength.

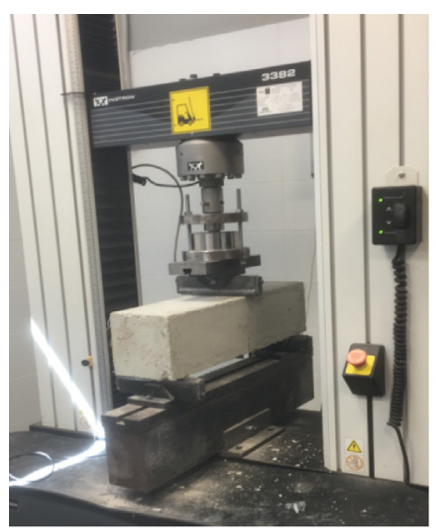

a)

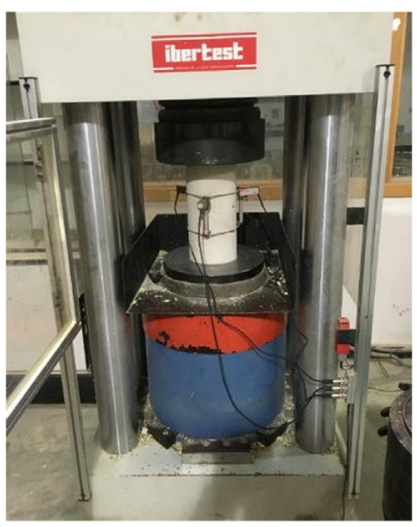

b)

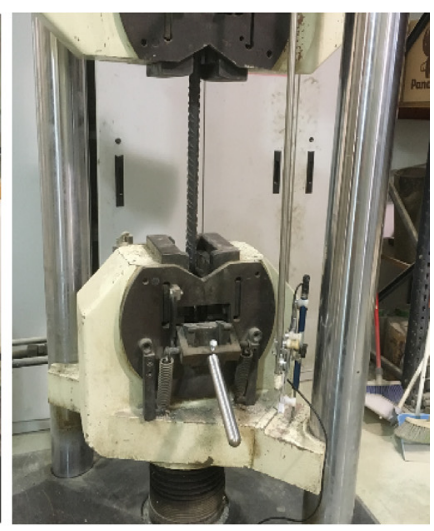

c)

Fig. 6. Test material setup: (a) Residual tensile strength, (b) Compression testing, (c) Reinforced tensile strength.

Table 4

Mechanical properties of beams.

\begin{tabular}{|c|c|c|c|c|c|c|c|c|c|c|c|c|c|c|c|c|c|c|c|}
\hline Beam & Type & Mix & $\begin{array}{l}\mathrm{f}_{\mathrm{cm}} \\
(\mathrm{MPa})\end{array}$ & & $\begin{array}{l}\mathrm{E}_{\mathrm{c}} \\
(\mathrm{MPa})\end{array}$ & & $\begin{array}{l}\mathrm{f}_{\mathrm{ctm}} \\
(\mathrm{MPa})\end{array}$ & & $\begin{array}{l}\text { Fibres }^{a} \\
\text { (U) }\end{array}$ & & $\begin{array}{l}\mathrm{fL} \\
(\mathrm{MPa})\end{array}$ & & $\begin{array}{l}\mathrm{f}_{\mathrm{R} 1}{ }^{\mathrm{b}} \\
(\mathrm{MPa})\end{array}$ & & $\begin{array}{l}\mathrm{f}_{\mathrm{R} 2} \\
(\mathrm{MPa})\end{array}$ & & $\begin{array}{l}\mathrm{f}_{\mathrm{R} 3}{ }^{\mathrm{b}} \\
(\mathrm{MPa})\end{array}$ & & $\begin{array}{l}\mathrm{f}_{\mathrm{R} 4} \\
(\mathrm{MPa})\end{array}$ \\
\hline OA1 & $\mathrm{RC}$ & $4-5$ & 41.78 & $(3 \%)$ & 29,440 & (5\%) & 3.30 & $(2 \%)$ & - & 4.71 & $(2 \%)$ & - & & & - & & & & \\
\hline $0 \mathrm{~A} 2$ & $\mathrm{RC}$ & 4 & 42.21 & (2\%) & 30,071 & (4\%) & 3.30 & (4\%) & - & 4.71 & (4\%) & - & & & - & & & & \\
\hline OB1 & $\mathrm{RC}$ & 6 & 38.30 & (3\%) & 29,273 & (2\%) & 3.00 & $(9 \%)$ & - & 4.29 & (9\%) & - & & & - & & & & \\
\hline OB2 & $\mathrm{RC}$ & $5-6$ & 39.83 & (5\%) & 28,908 & (3\%) & 3.15 & (7\%) & - & 4.50 & (7\%) & - & & & - & & & & \\
\hline $\mathrm{A} 1$ & $\mathrm{RC}$ & 1 & 39.75 & (2\%) & 30,275 & (1\%) & 3.25 & $(8 \%)$ & - & 4.65 & (8\%) & - & & & - & & & & \\
\hline A2 & $\mathrm{RC}$ & $1-2$ & 40.79 & $(4 \%)$ & 30,182 & (1\%) & 3.17 & $(6 \%)$ & - & 4.53 & $(6 \%)$ & - & & & - & & & & \\
\hline B1 & $\mathrm{RC}$ & 3 & 40.12 & (5\%) & 30,949 & $(2 \%)$ & 3.00 & $(3 \%)$ & - & 4.29 & $(3 \%)$ & - & & & - & & & & \\
\hline B2 & $\mathrm{RC}$ & $2-3$ & 40.97 & $(4 \%)$ & 30,495 & $(2 \%)$ & 3.05 & $(4 \%)$ & - & 4.35 & $(4 \%)$ & - & & & - & & & & \\
\hline 0AP1 & PFRC & $7-8$ & 43.12 & (5\%) & 29,361 & (3\%) & 3.34 & $(5 \%)$ & 48 & 4.77 & (5\%) & 2.97 & $(15 \%)$ & 4.26 & $(14 \%)$ & 4.60 & (15\%) & 4.74 & (15\%) \\
\hline OAP2 & PFRC & 7 & 44.91 & $(1 \%)$ & 30,164 & (1\%) & 3.38 & $(8 \%)$ & 49 & 4.83 & $(8 \%)$ & 2.85 & $(22 \%)$ & 4.05 & $(21 \%)$ & 4.32 & $(23 \%)$ & 4.40 & $(22 \%)$ \\
\hline 0BP1 & PFRC & 9 & 42.67 & $(1 \%)$ & 29,112 & (6\%) & 3.10 & $(1 \%)$ & 45 & 4.43 & (1\%) & 2.30 & (6\%) & 3.22 & $(10 \%)$ & 3.53 & $(11 \%)$ & 3.62 & $(10 \%)$ \\
\hline 0BP2 & PFRC & $8-9$ & 42.00 & $(2 \%)$ & 28,835 & (4\%) & 3.20 & $(4 \%)$ & 46 & 4.58 & (4\%) & 2.70 & $(18 \%)$ & 3.85 & $(20 \%)$ & 4.21 & $(20 \%)$ & 4.35 & (21\%) \\
\hline AP1 & PFRC & $10-11$ & 43.96 & $(2 \%)$ & 30,432 & (4\%) & 2.98 & $(5 \%)$ & 44 & 4.26 & (5\%) & 2.61 & $(17 \%)$ & 3.64 & $(20 \%)$ & 4.10 & $(19 \%)$ & 4.10 & (21\%) \\
\hline AP2 & PFRC & 10 & 44.62 & $(3 \%)$ & 30,178 & (2\%) & 3.08 & $(6 \%)$ & 40 & 4.40 & (6\%) & 2.70 & $(27 \%)$ & 3.74 & $(32 \%)$ & 4.16 & $(32 \%)$ & 4.10 & (35\%) \\
\hline BP1 & PFRC & 12 & 44.96 & $(3 \%)$ & 30,571 & $(4 \%)$ & 3.42 & $(13 \%)$ & 55 & 4.89 & $(13 \%)$ & 3.09 & $(7 \%)$ & 4.49 & $(4 \%)$ & 5.10 & $(13 \%)$ & 5.42 & $(12 \%)$ \\
\hline BP2 & PFRC & $11-12$ & 44.22 & $(3 \%)$ & 30,628 & $(4 \%)$ & 3.16 & $(13 \%)$ & 53 & 4.51 & $(13 \%)$ & 2.80 & $(13 \%)$ & 4.02 & $(14 \%)$ & 4.57 & $(16 \%)$ & 4.75 & $(18 \%)$ \\
\hline
\end{tabular}

Coefficients of variation are shown in brackets ().

a Fibres per square decimetre.

b Residual flexural-tensile strength $\left(f_{R 1}\right): 0.5 \mathrm{~mm}$ for CMOD and $\left(f_{R 3}\right)$ and $2.5 \mathrm{~mm}$ for CMOD.

process. Figs. 11 and 12 represent a panoramic view of all four pictures taken with each digital camera. Distortion was corrected before merging pictures.

In all the beams series, and as seen in Fig. 10, the same stiffness was initially observed, which changed according to new crack propagation. The first crack observed during the test appeared upon an average load of $73 \mathrm{kN}$ for series A1, $78 \mathrm{kN}$ for series A2, $60 \mathrm{kN}$ for series B1 and $55 \mathrm{kN}$ for series B2.

Diagonal tension failure was observed in all the beams (RC and PFRC) that had no web reinforcement. The RC beams w/o stirrups showed a single main critical diagonal crack between $0.2 \mathrm{~mm}$ and $0.5 \mathrm{~mm}$ in width before collapsing, which produced an 
Table 5

Reinforcement properties.

\begin{tabular}{llll}
\hline Diam. $(\mathrm{mm})$ & Area $\left(\mathrm{mm}^{2}\right)$ & $\mathrm{f}_{\mathrm{y}}(\mathrm{MPa})$ & $\mathrm{f}_{\mathrm{u}}(\mathrm{MPa})$ \\
\hline 8 & 50.27 & 518 & 660 \\
10 & 78.54 & 526 & 670 \\
12 & 113.10 & 529 & 640 \\
20 & 314.16 & 579 & 662 \\
25 & 490.87 & 579 & 662 \\
\hline
\end{tabular}

instantaneous brittle-like failure with no ductility when the peak load was reached. Vertical flexural cracks began to inflect towards the load point at about $41 \%$ of the peak load on average. After the main critical diagonal crack had formed, it began to propagate quickly ( $45^{\circ}$ slope) through the web of beams until longitudinal compression reinforcement took place, and then propagated rapidly as a large horizontal crack up to the beam-bearing plate.

Conversely, the PFRC w/o stirrups showed larger cracks, in the order of $0.25 \mathrm{~mm}$, on both sides of the beam, and several main cracks over $6 \mathrm{~mm}$ before collapsing, which also produced reduced loads and instantaneous failure, but they were less brittle-like than their corresponding RC beam. The vertical flexural cracks began to inflect towards the load point at $24 \%$ of the peak load on average. The main diagonal tension cracks were formed at approximately $71 \%$ of the peak load on average, and presented a more direct inclination between the load point and the support.

The RC and PFRC beams with stirrups failed to shearcompression, except for BP2, which presented a flexion MOF. However, beam AP2 displayed major longitudinal reinforcement deformations upon peak load, which exceeded the yield steel limit (2.8 $\left.\times 10^{3}\right)$.

The RC beams showed several diagonal-tension cracks with a crack width of around 3-5 mm upon peak load. Diagonal cracks extended upwards and downwards while load increased. Failure

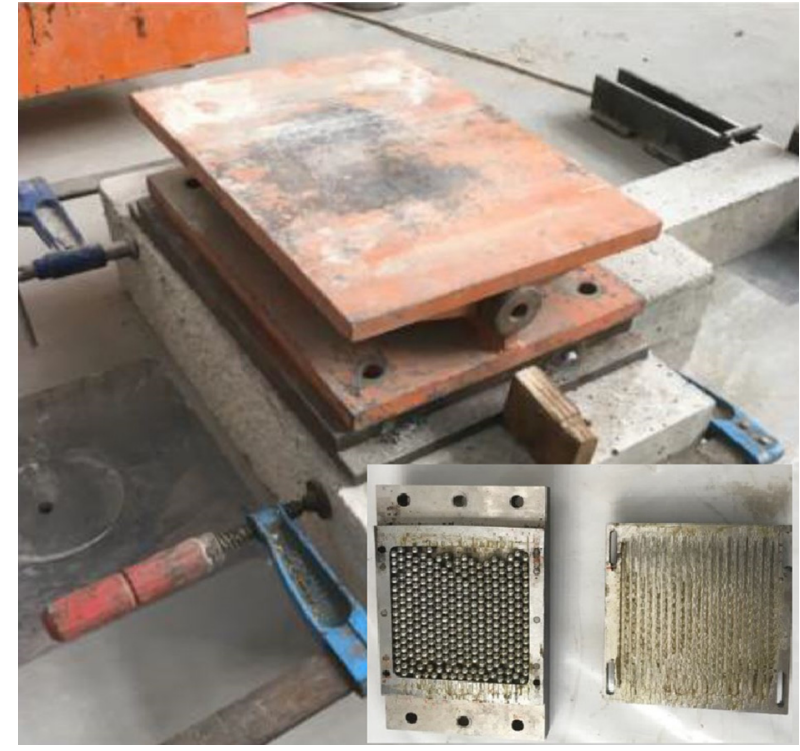

Fig. 9. Roller Support

occurred when one of the diagonal cracks reached the compression chord and caused the concrete to crush.

The PFRC beams with stirrups exhibited a much greater cracking pattern than the RC beams, with less separated cracks, and initially with a narrower width. The vertical flexural cracks began to inflect towards the load point at about $25 \%$ of the peak load. Several diagonal tension cracks opened gradually to $1 \mathrm{~mm}$ in the peak load as load increased. Failure started when the diagonal tension cracks reached the compression chords and began to split the concrete below the load application point.

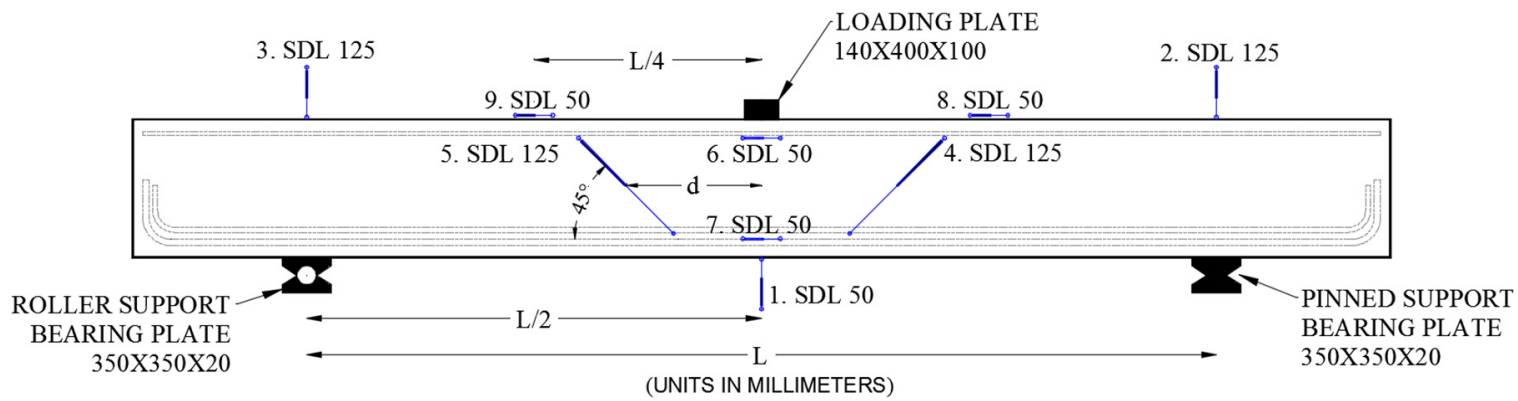

Fig. 7. Beams Test Setup.

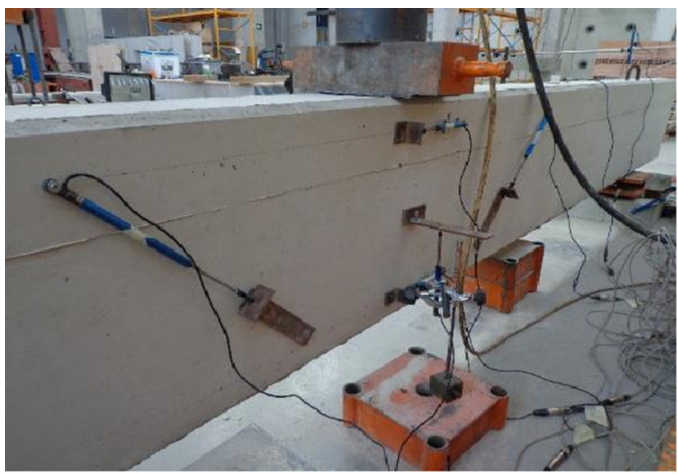

a)

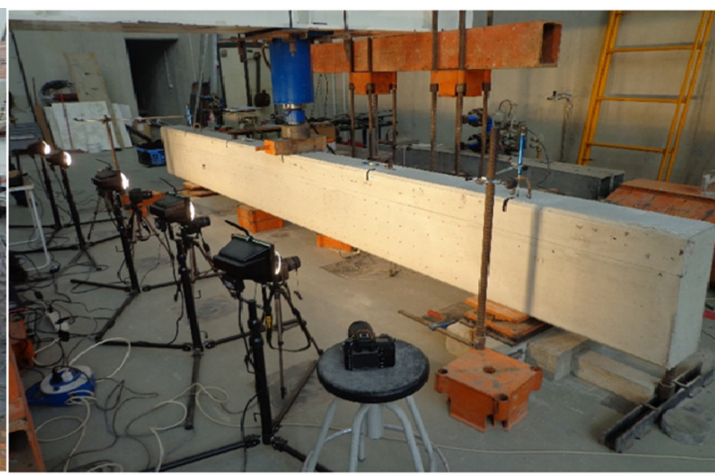

b)

Fig. 8. a) Shear Inclined LVDTs and b) Cameras Setup. 
Table 6

Test beam results.

\begin{tabular}{|c|c|c|c|c|c|c|c|c|c|}
\hline Beam & MOF & $\mathrm{P}_{\mathrm{u}}(\mathrm{kN})$ & $\mathrm{V}_{\mathrm{u}}(\mathrm{kN})$ & $v_{u}(\mathrm{MPa})$ & $\delta_{\mathrm{u}}(\mathrm{mm})$ & $\varepsilon_{\mathrm{c}} \times 10^{3}$ & $\varepsilon_{\mathrm{t}} \times 10^{3}$ & $\mathrm{w}_{\mathrm{s}}(\mathrm{mm})$ & $\mathrm{w}_{\mathrm{f}}(\mathrm{mm})$ \\
\hline OA1 & D-T & 312.11 & 160.96 & 1.12 & 5.74 & -0.33 & 1.40 & 0.30 & 0.25 \\
\hline OA2 & D-T & 339.03 & 176.29 & 1.22 & 12.06 & -0.65 & 2.92 & 0.50 & 0.30 \\
\hline OB1 & D-T & 274.97 & 141.17 & 1.30 & 7.48 & -0.65 & 0.79 & 0.20 & 0.15 \\
\hline OB2 & D-T & 226.37 & 118.28 & 1.10 & 10.01 & -0.51 & 1.29 & 0.30 & 0.25 \\
\hline A1 & $\mathrm{V}-\mathrm{C}$ & 472.71 & 241.25 & 1.67 & 16.31 & -0.27 & 2.15 & 4.00 & 0.25 \\
\hline $\mathrm{A} 2$ & V-C & 478.39 & 245.97 & 1.71 & 25.96 & -1.79 & 1.93 & 5.00 & 0.40 \\
\hline B1 & V-C & 468.01 & 237.67 & 2.19 & 17.69 & -2.12 & 2.50 & 3.50 & 0.30 \\
\hline B2 & $\mathrm{V}-\mathrm{C}$ & 439.57 & 224.86 & 2.07 & 31.62 & -3.00 & 2.47 & 3.00 & 0.40 \\
\hline OAP1 & D-T & 446.68 & 228.24 & 1.58 & 15.81 & -0.43 & 2.19 & 6.00 & 0.25 \\
\hline OAP2 & D-T & 486.26 & 249.91 & 1.73 & 28.02 & -1.93 & 2.57 & 6.00 & 0.20 \\
\hline OBP1 & D-T & 361.73 & 184.55 & 1.71 & 15.30 & -0.72 & 2.04 & 7.00 & 0.20 \\
\hline OBP2 & D-T & 295.60 & 152.90 & 1.42 & 18.02 & -1.28 & 2.02 & 6.00 & 0.25 \\
\hline AP1 & $\mathrm{V}-\mathrm{C}$ & 695.30 & 352.54 & 2.43 & 29.78 & -3.96 & 2.20 & 2.50 & 1.00 \\
\hline AP2 & $\mathrm{V}-\mathrm{C}$ & 678.60 & 346.07 & 2.39 & 35.49 & -3.54 & 4.29 & 2.00 & 0.30 \\
\hline BP1 & $\mathrm{V}-\mathrm{C}$ & 555.56 & 281.43 & 2.56 & 18.60 & -1.61 & 2.62 & 1.50 & 0.20 \\
\hline BP2 & $\mathrm{F}-\mathrm{C}$ & 487.37 & 248.77 & 2.29 & 32.37 & -0.82 & 3.73 & 1.00 & 0.30 \\
\hline
\end{tabular}

All the measurements were taken at peak load.
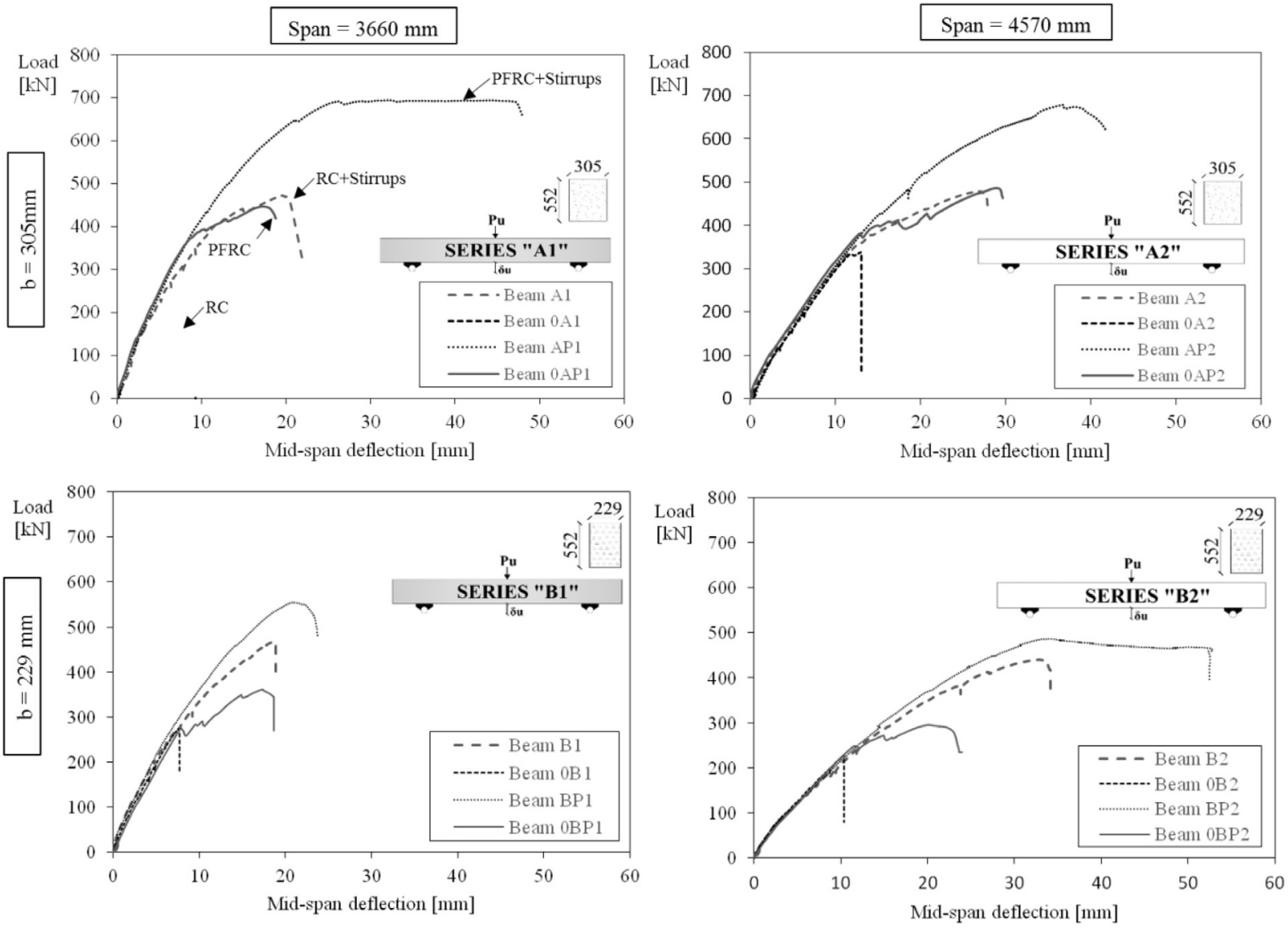

Fig. 10. Load-deflection response. RC vs. PFRC fibres.

\section{Analysis of the results}

\subsection{Comparison of the Bresler-Scordelis, Toronto, and ICITECH beams}

The experimental programme run in the present research used six beams, which had been previously tested by Bresler-Scordelis [1] and Vecchio-Shim [2]. Fig. 13 includes the graphical comparisons made of the six beams.
A similar trend in the load-deflection responses was observed, as was a similar MOF to those observed in the corresponding Bresler-Scordelis and Vecchio-Shim et al. beams, despite there being certain differences in the material properties. Table 7 shows the comparisons of all three tests. The ratio of the peak load between the ICITECH and Bresler [1] beams was in the order of 0.91 to 1.07 , with a $6.1 \%$ coefficient of variation, which generally achieved greater deflection upon peak load compared to the 

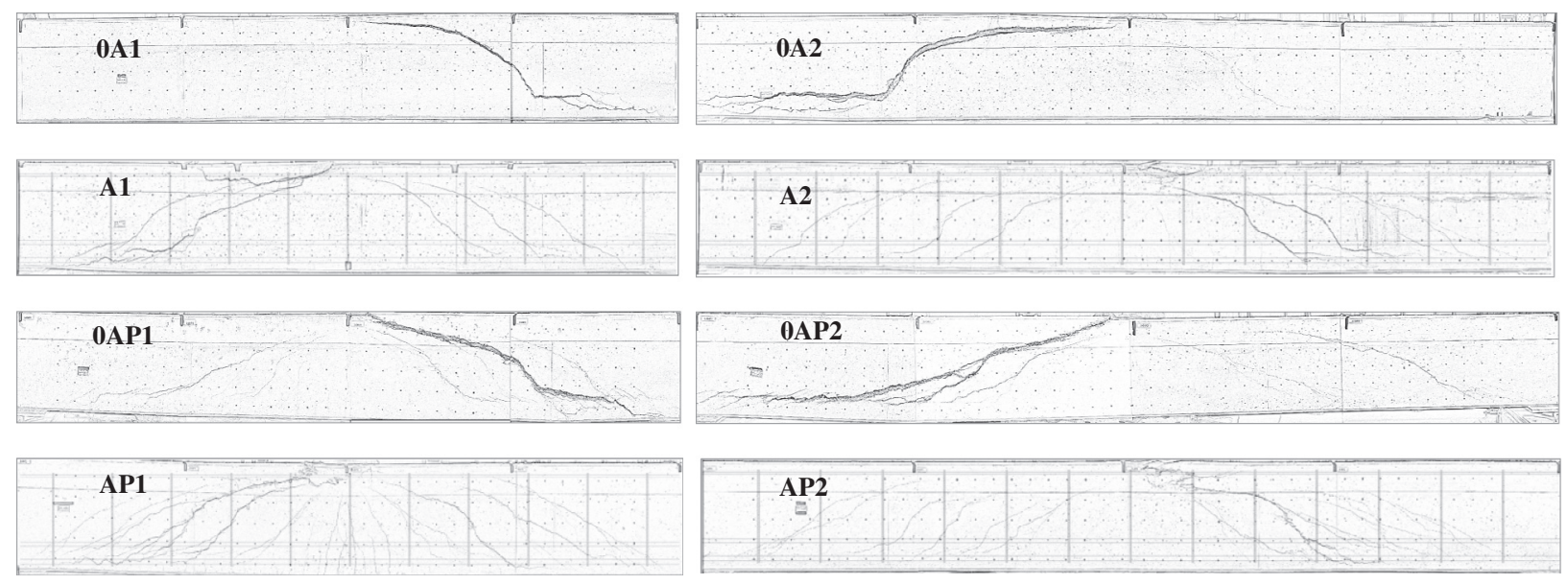

Fig. 11. ICITECH Beams upon failure. Series A.
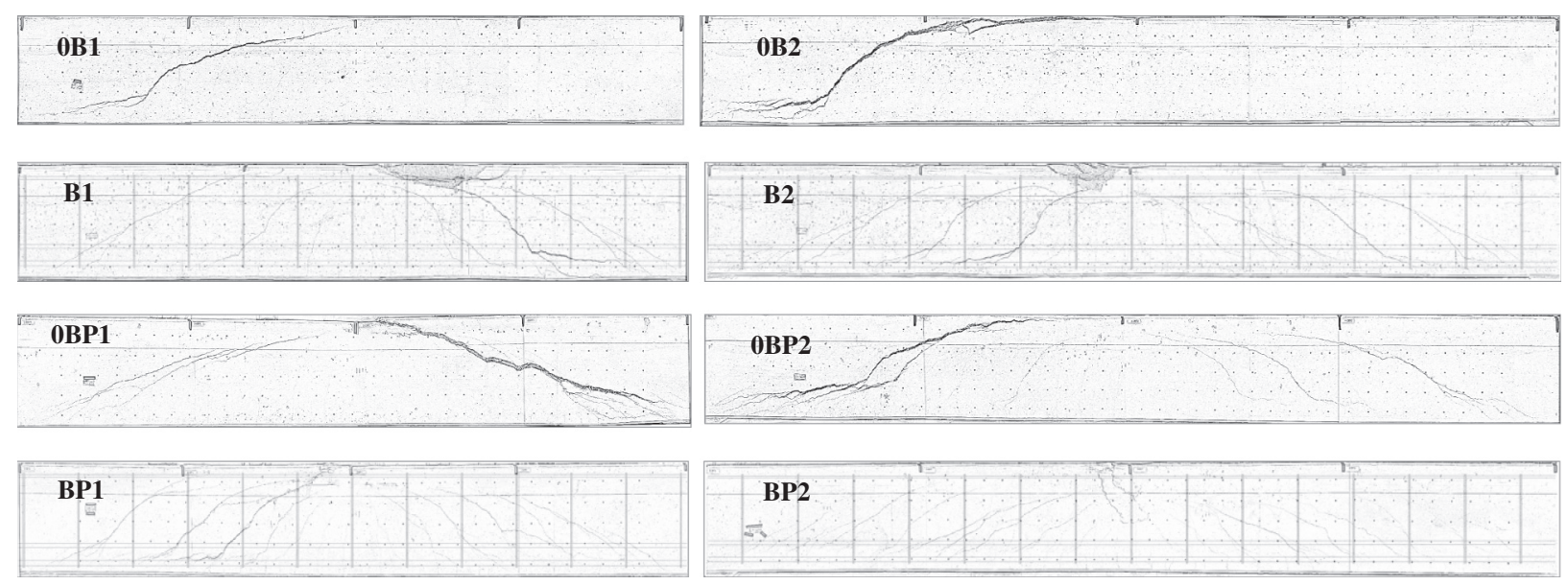

Fig. 12. ICITECH Beams upon failure. Series B.

respective Bresler beams. The Vecchio-Shim beams generally reached less loads and more deflection than the present experimentation beams. Despite the amount of transverse reinforcement being the same as that used by Bresler (0.1-0.148\%). Bresler et al. used a diameter of $6.4 \mathrm{~mm}$ and spacing between $190 \mathrm{~mm}$ and 210 $\mathrm{mm}$. The ICITECH beams used 8-mm-diameter stirrups and spacing between $300 \mathrm{~mm}$ and $330 \mathrm{~mm}$. This meant that spacing was wider than the effective depth used by the Bresler beams. One consequence of increasing the transverse reinforcement spacing was that fewer stirrups crossed the diagonal crack, which changed the stiffness of beams to a small magnitude, but not their resistance, as shown in Fig. 13. The ICITECH beams presented generally lesser stiffness than the corresponding Bresler beams, but greater stiffness than the Vecchio ones.

Another modification made to the material that influenced beam behaviour, compared with the Bresler beams, was the small difference in the amount of longitudinal compression and tensile reinforcement. The Bresler beams contained approximately 4.6\% more tensile reinforcement and $17 \%$ less compression reinforcement than the respective ICITECH beams.

\subsection{Analysis of the PFRC beams}

The ductility achieved by the PFRC beams (see Table 6 and Fig. 10) was greater and ultimate load increased significantly compared with the RC beams. This happened in the PFRC beams both with and w/o stirrups. Improvements in ductility and peak load became more evident in the A-section beams as many fibres crossed the diagonal cracks.

We also observed that the PFRC beams w/o transverse reinforcement (OAP1 and 0AP2) achieved a similar peak load and deflection to their corresponding RC beams (A1 and A2), but their stiffness was maintained for longer than the RC beams as fibres enhanced the aggregate interlocking effect. This behaviour was not observed in the B-section beams because fewer fibres crossed the diagonal cracks as they had a narrower section width than the A series beams.

The distribution of shear cracks was also generally random, and no clear pattern was found between beams. However, the macrosynthetic fibres allowed several diagonal cracks to develop and less localised cracking was observed with the PFRC beams versus the RC beams w/o stirrups. The diagonal cracks in the RC beams developed mainly from a shear crack, which came to approximately $41 \%$ of peak load, while the main diagonal crack in the PFRC beams appeared as a new crack at approximately $70 \%$ of peak load, even though shear cracks began to appear at $24 \%$ of peak load. This effect is possibly because macrofibres helped to redistribute shear stresses, and to improve the bridging action between crack faces.

A synergy effect among concrete, steel and fibre was also identified in the PFRC beams. Table 8 shows the experimental synergy of each beam series, in which each resistance was decoupled in concrete, steel and fibre, and was finally normalised according to the corresponding square root of concrete compressive strength. The synergy effect occurred in series A1 and A2. The following 

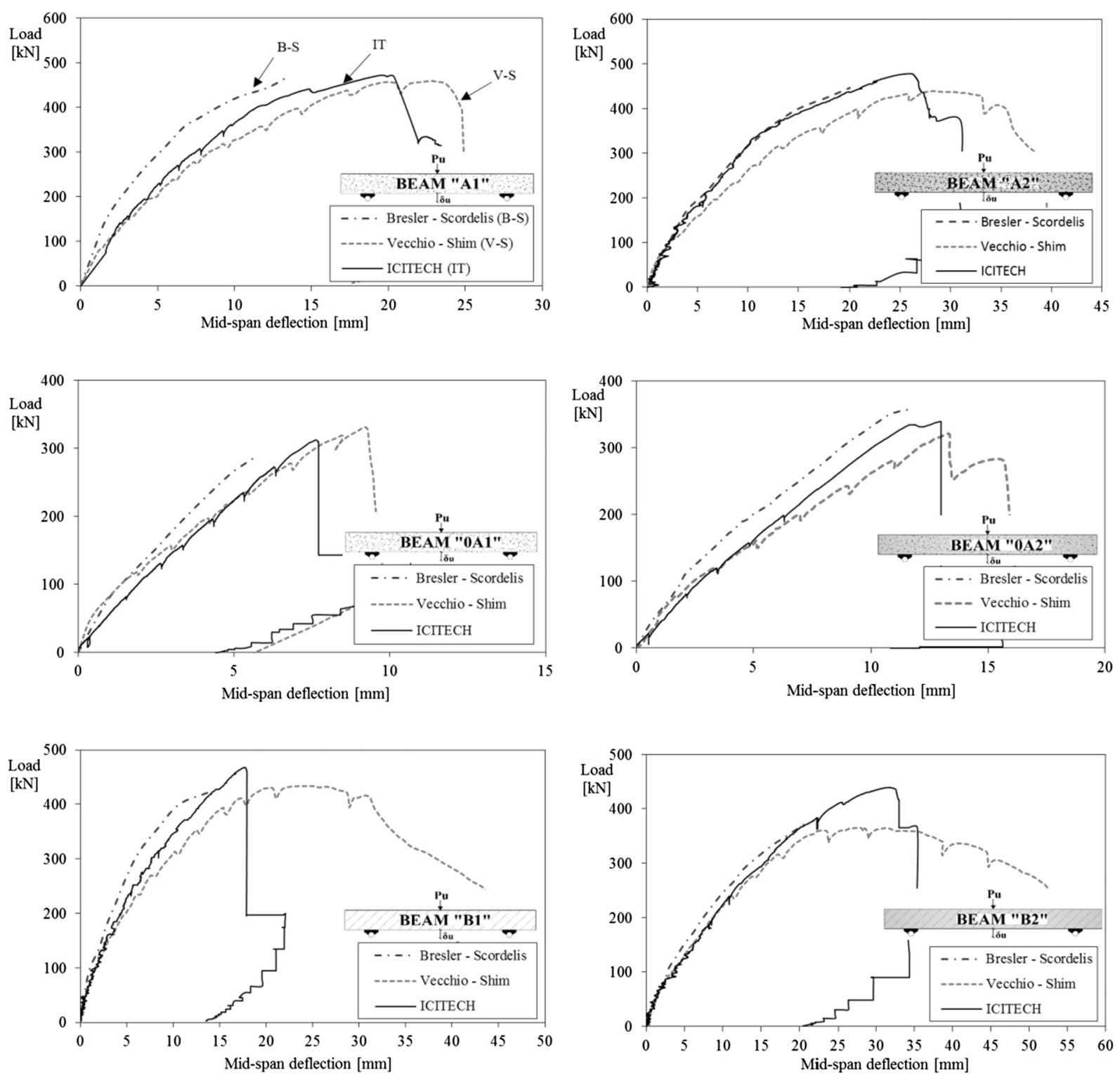

Fig. 13. Comparison of the Bresler-Scordelis, Vecchio-Shim and ICITECH beams.

Table 7

Comparisons made of the ICITECH, Bresler-Scordelis and Vecchio-Shim beams.

\begin{tabular}{|c|c|c|c|c|c|c|c|}
\hline \multirow[t]{2}{*}{ Beam } & \multicolumn{2}{|l|}{ ICITECH } & \multicolumn{2}{|c|}{ Bresler-Scordelis } & \multicolumn{2}{|c|}{ Vecchio-Shim } & \multirow[t]{2}{*}{$\mathrm{P}_{\mathrm{u}}(\mathrm{BS}) / \mathrm{P}_{\mathrm{u}}(\mathrm{IT})}$. \\
\hline & $\mathrm{P}_{\mathrm{u}}(\mathrm{IT})(\mathrm{kN})$ & $\delta_{\mathrm{u}}(\mathrm{IT})(\mathrm{mm})$ & $\mathrm{P}_{\mathrm{u}}(\mathrm{BS})(\mathrm{kN})$ & $\delta_{\mathrm{u}}(\mathrm{BS})(\mathrm{mm})$ & $\mathrm{P}_{\mathrm{u}}(\mathrm{VS})(\mathrm{kN})$ & $\delta_{\mathrm{u}}(\mathrm{VS})(\mathrm{mm})$ & \\
\hline OA1 & 312 & 5.74 & 334 & 6.6 & 331 & 9.1 & 1.07 \\
\hline $0 \mathrm{~A} 2$ & 339 & 12.09 & 356 & 11.7 & 320 & 13.2 & 1.05 \\
\hline A1 & 472 & 17.03 & 467 & 12.2 & 459 & 18.8 & 0.99 \\
\hline A2 & 478 & 31.3 & 489 & 22.9 & 439 & 29.1 & 1.02 \\
\hline B1 & 468 & 17.87 & 445 & 13.7 & 434 & 22 & 0.95 \\
\hline B2 & 439 & 31.52 & 400 & 20.8 & 365 & 31.6 & 0.91 \\
\hline
\end{tabular}

results were obtained when evaluating the synergy in both series: A1 beams $0.03 \mathrm{MPa} / \mathrm{MPa}, \mathrm{A} 2$ beams $0.02 \mathrm{MPa} / \mathrm{MPa}$. This scenario respectively represents a greater efficiency in fibre resistance of $49 \%$ and $28 \%$. This synergy effect did not occur in series B1 and B2, where the synergy was negative (see Table 8 ): B1 beams -0.02 $\mathrm{MPa} / \mathrm{MPa}$, and $\mathrm{B} 2$ beams $-0.02 \mathrm{MPa} / \mathrm{MPa}$. This finding respectively represents a decreasing fibre resistance of $30 \%$ and $54 \%$. This behaviour probably occurred because the width of section $B$, compared to section A, was narrower, and few fibres bridged cracks. It is worth noting that this synergy effect occurred when contributions of both fibres and stirrups are similar to one another, which was the case of series A, but not series B where the contribution of fibres was less than half the contribution of steel (see Table 8 ). The results also indicated that a synergy did not always occur. Further research should be conducted to increase the experience about a synergy effect between fibres and stirrups.

It is important to mention that although the MOF of the PFRC non-stirrup beams remained unaltered compared with their 
Table 8

The obtained experimental synergy.

\begin{tabular}{|c|c|c|c|c|c|c|c|c|c|}
\hline Beam & $\mathrm{Pu}(\mathrm{kN})$ & $\mathrm{V}_{\mathrm{u}}(\mathrm{kN})$ & $v_{u}(\mathrm{MPa})$ & $22 \frac{v_{u}}{\sqrt{\mathrm{f}_{\mathrm{cm}}}}$ & $6 v_{c}$ & $5 v_{s}$ & $v_{f}$ & $\Sigma^{1}$ & Synergy $^{2}$ \\
\hline OA1 & 312.11 & 156.06 & 1.1169 & 0.17 & 0.17 & - & - & - & \\
\hline $\mathrm{A} 1$ & 472.71 & 236.35 & 1.6741 & 0.27 & - & 0.09 & - & - & \\
\hline OAP1 & 446.68 & 223.34 & 1.5824 & 0.24 & - & - & 0.07 & - & \\
\hline AP1 & 695.30 & 347.65 & 2.4334 & 0.37 & - & - & - & 0.33 & 0.033 \\
\hline $\mathrm{OA} 2$ & 339.03 & 169.52 & 1.2184 & 0.19 & 0.19 & - & - & - & \\
\hline A2 & 478.39 & 239.19 & 1.7068 & 0.27 & - & 0.08 & - & - & \\
\hline OAP2 & 486.26 & 243.13 & 1.7341 & 0.26 & - & - & 0.07 & - & \\
\hline AP2 & 678.60 & 339.30 & 2.3918 & 0.36 & - & - & - & 0.34 & 0.020 \\
\hline OB1 & 274.97 & 137.49 & 1.3047 & 0.21 & 0.21 & - & - & - & \\
\hline B1 & 468.01 & 234.00 & 2.1878 & 0.35 & - & 0.13 & - & - & \\
\hline OBP1 & 361.73 & 180.86 & 1.7124 & 0.26 & - & - & 0.05 & - & \\
\hline BP1 & 555.56 & 277.78 & 2.5550 & 0.38 & - & - & - & 0.40 & -0.016 \\
\hline OB2 & 226.37 & 113.19 & 1.0962 & 0.17 & 0.17 & - & - & - & \\
\hline B2 & 439.57 & 219.78 & 2.0699 & 0.32 & - & 0.15 & - & - & \\
\hline OBP2 & 295.60 & 147.80 & 1.4230 & 0.22 & - & - & 0.05 & - & \\
\hline BP2 & 487.37 & 243.69 & 2.2890 & 0.34 & - & - & - & 0.37 & -0.025 \\
\hline
\end{tabular}

${ }^{1} \Sigma=v_{c}+v_{s}+v_{f}$.

2 Synergy $=\frac{v_{u}}{\sqrt{\mathrm{f}_{\mathrm{cm}}}}-\Sigma$.

corresponding RC beams, the behaviour of the main diagonal shear crack differed as it was less fragile and more predictable. Thus, it could be classified as a controlled diagonal tension (C-D-T) MOF. The differences between D-T and C-D-T can be watched in Video 1 (the web version paper), which corresponds to the A2 series. The diagonal crack opening measured upon peak load was significantly larger and ranged between $6 \mathrm{~mm}$ and $7 \mathrm{~mm}$ in the PFRC beams w/o stirrups (OAP1, OAP2, OBP1 and OBP2) versus the RC beams, which were between 0.3 and $0.5 \mathrm{~mm}$. The inclination and shape of the main diagonal cracks also changed compared with the PFRC and RC beams w/o transverse reinforcement (see Figs. 11 and 12). The PFRC diagonal cracks were less curved and more direct from the loading point to the support, while the RC beams clearly displayed a more curved crack.
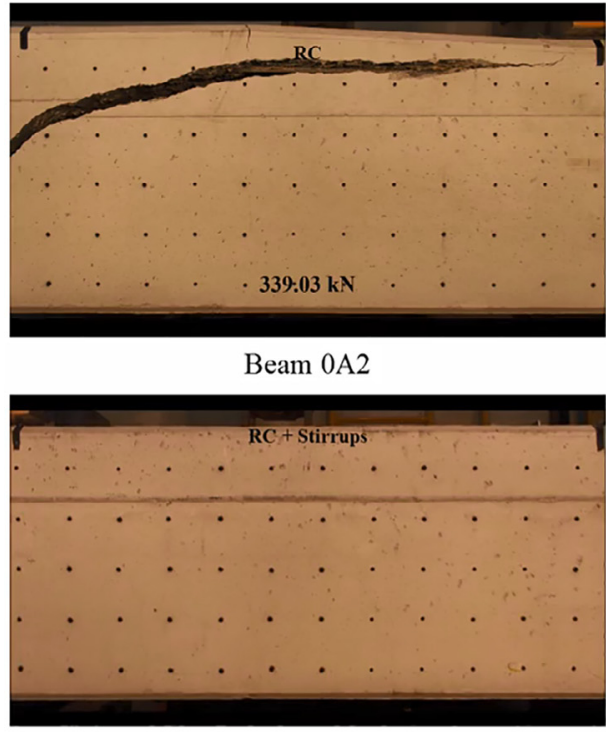

Beam A2 compression (F-C) MOF because the main shear crack did not clearly progress towards the compression chord.

\section{Concluding remarks}

Sixteen full-scale beams were tested by applying a concentrated load at the mid-span. The main investigated parameters were the influence of macro-synthetic fibres $\left(10 \mathrm{~kg} / \mathrm{m}^{3}, \mathrm{~V}_{\mathrm{f}}=1.1 \%\right)$ on shear resistance, and its effect on the MOF. The beams tested by BreslerScordelis at the University of Berkeley in the early 1960s inspired the geometry of the present beams, but with certain material differences.

The main conclusions drawn from the present study are as follows:

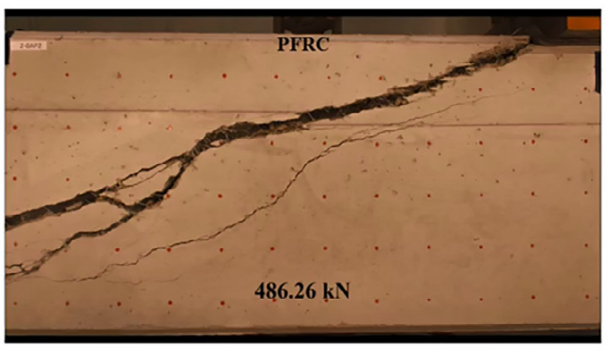

Beam 0AP2

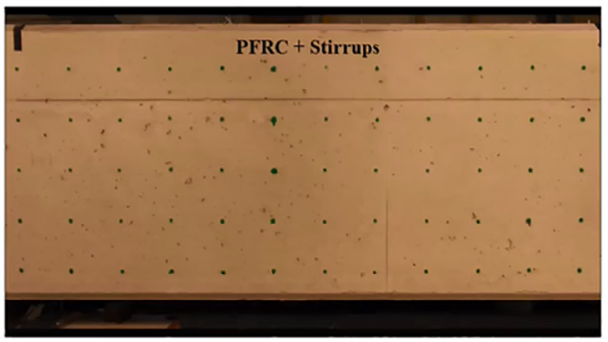

Beam AP2

Video 1.

It is interesting to note that beams AP1, AP2 and BP1 failed in V-C. In the particular case of the AP1 beam, shear-compression failure occurred with the previous yielding of longitudinal reinforcement in tension (see Fig. 10). Longitudinal reinforcement yielding was also observed with the BP2 beam, but ended in a flexure- a) Shear-critical Bresler-Scordelis, Vecchio-Shim and ICITECH reinforced concrete beams showed a similar load-deflection response, a similar ultimate load, and a similar MOF.

b) Macro-synthetic fibres significantly improve beam behaviour by increasing the ultimate load and improving ductility. 
c) The inclusion of macro-synthetic fibres in reinforced concrete beams $\mathrm{w} / \mathrm{o}$ transverse reinforcement is unable to change the MOF, but can change MOF performance by presenting critical diagonal crack openings upon failure within a range of several millimetres, plus less fragile behaviour.

d) The macro-synthetic fibres added to the beams w/o transverse reinforcement achieved a similar response in some cases to those observed in the reinforced concrete beams with transverse reinforcement.

e) The macro-synthetic FRC beams, used in combination with transverse reinforcement, achieved a higher ultimate load versus the beams $\mathrm{w} / \mathrm{o}$ fibres. A synergy effect in shear strength terms between the fibres and transverse reinforcement was observed in two of the four beam series, which evidently shows that a synergy does not always occur. In some cases, even yielding longitudinal reinforcement in tension was achieved.

f) Macro-synthetic fibres can serve as an effective mechanism of shear transfer.

\section{Acknowledgment}

This work forms part of the PAID-06-11 programme supported by the Generalitat Valenciana.

\section{References}

[1] B. Bresler, A.C. Scordelis, Shear strength of reinforced concrete beams, J. Am. Concr. Inst. 60 (1963) 51-72.

[2] F.J. Vecchio, W. Shim, Experimental and analytical reexamination of classic concrete beam tests, J. Struct. Eng. 130 (2004) 460-469, https://doi.org/ 10.1061/(ASCE)0733-9445(2004) 130:3(460).

[3] A.R. Khaloo, N. Kim, Influence of concrete and fiber characteristics on behavior of steel fiber reinforced concrete under direct shear, ACI Mater. J. 94 (1997) 592-601.

[4] M. diPrisco, R. Felicetti, Some results on punching shear in plain and fibrereinforced micro-concrete slabs, Mag. Concr. Res. 49 (1997) 201-219. papers2://publication/uuid/D0655E73-19E2-4A2B-AF58-E277C892310F.

[5] E. Cuenca, J. Echegaray-Oviedo, P. Serna, Influence of concrete matrix and type of fiber on the shear behavior of self-compacting fiber reinforced concrete beams, Compos. Part B Eng. 75 (2015) 135-147, https://doi.org/10.1016/ j.compositesb.2015.01.037.

[6] A. Amin, S.J. Foster, Shear strength of steel fibre reinforced concrete beams with stirrups, Eng. Struct. 111 (2016) 323-332, https://doi.org/10.1016/j. engstruct.2015.12.026.

[7] A. Conforti, F. Minelli, A. Tinini, G.A. Plizzari, Influence of polypropylene fibre reinforcement and width-to-effective depth ratio in wide-shallow beams, Eng. Struct. 88 (2015) 12-21, https://doi.org/10.1016/j.engstruct.2015.01.037.

[8] Y. Yang, J. Walraven, J. Den Uijl, Shear Behavior of Reinforced Concrete Beams without Transverse Reinforcement Based on Critical Shear Displacement, 143 (2017) 1-13, doi:10.1061/(ASCE)ST.1943-541X.0001608.

[9] S. Altoubat, A. Yazdanbakhsh, K.A. Rieder, Shear behavior of macro-synthetic fiber-reinforced concrete beams without stirrups, ACI Mater. J. 106 (2009) 381389.

[10] D.R. Sahoo, K. Maran, A. Kumar, Effect of steel and synthetic fibers on shear strength of RC beams without shear stirrups, Constr. Build. Mater. 83 (2015) 150-158, https://doi.org/10.1016/j.conbuildmat.2015.03.010.

[11] K.S. Kim, D.H. Lee, J.H. Hwang, D.A. Kuchma, Shear behavior model for steel fiber-reinforced concrete members without transverse reinforcements, Compos. Part B Eng. 43 (2012) 2324-2334, https://doi.org/10.1016/ j.compositesb.2011.11.064.

[12] T. Tahenni, M. Chemrouk, T. Lecompte, Effect of steel fibers on the shear behavior of high strength concrete beams, Constr. Build. Mater. 105 (2016) 14 28, https://doi.org/10.1016/j.conbuildmat.2015.12.010.

[13] F. Zhang, Y. Ding, J. Xu, Y. Zhang, W. Zhu, Y. Shi, Shear strength prediction for steel fiber reinforced concrete beams without stirrups, Eng. Struct. 127 (2016) 101-116, https://doi.org/10.1016/j.engstruct.2016.08.012.

[14] F. Soltanzadeh, A. Edalat-Behbahani, J.A.O. Barros, H. Mazaheripour, Effect of fiber dosage and prestress level on shear behavior of hybrid GFRP-steel reinforced concrete I-shape beams without stirrups, Compos. Part B Eng. 102 (2016) 57-77, https://doi.org/10.1016/j.compositesb.2016.07.003.

[15] F. Soltanzadeh, A.E. Behbahani, H. Mazaheripour, J.A.O. Barros, Shear resistance of SFRSCC short-span beams without transversal reinforcements, Compos. Struct. 139 (2016) 42-61, https://doi.org/10.1016/j.compstruct.2015.11.067.
[16] E. Cuenca, P. Serna, Shear behavior of prestressed precast beams made of selfcompacting fiber reinforced concrete, Constr. Build. Mater. 45 (2013) 145-156, https://doi.org/10.1016/j.conbuildmat.2013.03.096.

[17] H.M.B., R.N. Swamy, The Effectiveness of Steel Fibers as Shear Reinforcement, Concr. Int., 7 (n.d.).

[18] J. Walvaren, Model Code 2010, final drafts, FIB Bull. 1 \& 2 (2012) 105.

[19] ACI, Building Code Requirements for Structural Concrete (ACI 318-14) and Commentary (ACI 318R-14), 2014, doi:10.1016/0262-5075(85)90032-6.

[20] M. Di Prisco, G. Plizzari, L. Vandewalle, "MC2010: Overview on the shear provisions for FRC", in: Work. SALO, 2010, pp. 61-76.

[21] J. Susetyo, P. Gauvreau, F.J. Vecchio, Effectiveness of steel fiber as minimum shear reinforcement, ACI Struct. J. 108 (2011) 488.

[22] F. Bencardino, L. Rizzuti, G. Spadea, R.N. Swamy, Experimental evaluation of fiber reinforced concrete fracture properties, Compos. Part B Eng. 41 (2010) 17-24, https://doi.org/10.1016/j.compositesb.2009.09.002.

[23] Y. Ding, Z. You, S. Jalali, The composite effect of steel fibres and stirrups on the shear behaviour of beams using self-consolidating concrete, Eng. Struct. 33 (2011) 107-117, https://doi.org/10.1016/j.engstruct.2010.09.023.

[24] S.A. Ashour, G.S. Hasanain, F.F. Wafa, Shear behavior of high-strength fiber reinforced concrete beams, Struct. J. 89 (1992) 176-184.

[25] K. Marar, Ö. Eren, H. Roughani, The influence of amount and aspect ratio of fibers on shear behaviour of steel fiber reinforced concrete, KSCE J. Civ. Eng. (2016) 1-7, https://doi.org/10.1007/s12205-016-0787-2.

[26] D.R. Sahoo, S. Bhagat, T.C.V. Reddy, Experimental study on shear-span to effective-depth ratio of steel fiber reinforced concrete T-beams, Mater. Struct. 49 (2016) 3815-3830, https://doi.org/10.1617/s11527-015-0756-6.

[27] E. Cuenca, P. Serna, Failure modes and shear design of prestressed hollow core slabs made of fiber-reinforced concrete, Compos. Part B Eng. 45 (2013) $952-$ 964, https://doi.org/10.1016/j.compositesb.2012.06.005.

[28] E. Cuenca, P. Serna, Shear behavior of Self-Compacting concrete and FiberReinforced concrete Push-Off specimens, RILEM Bookseries, 1 (2010), pp. 429438, doi:10.1007/978-90-481-9664-7_36.

[29] M. Imam, L. Vandewalle, F. Mortelmans, D. Van Gemert, Shear domain of fibrereinforced high-strength concrete beams, Eng. Struct. 19 (1997) 738-747, https://doi.org/10.1016/S0141-0296(96)00150-2.

[30] G.J. Parra-Montesinos, Shear strength of beams with deformed steel fibers, Concr. Int. 28 (2006) 57-66.

[31] F. Minelli, A. Conforti, E. Cuenca, G. Plizzari, Are steel fibres able to mitigate or eliminate size effect in shear?, Mater Struct. 47 (2014) 459-473, https://doi. org/10.1617/s11527-013-0072-y.

[32] J. Navarro-Gregori, E.J. Mezquida-Alcaraz, P. Serna-Ros, J. Echegaray-Oviedo, Experimental study on the steel-fibre contribution to concrete shear behaviour, Constr. Build. Mater. 112 (2016) 100-111, https://doi.org/ 10.1016/ j.conbuildmat.2016.02.157

[33] J. Echegaray-Oviedo, J. Navarro-Gregori, E. Cuenca, P. Serna, Upgrading the push-off test to study the mechanisms of shear transfer in FRC elements, in: Proc. 8th Int. Conf. Fract. Mech. Concr. Concr. Struct. Fram. 2013, pp. 10121021.

[34] E. Cuenca, P. Serna, G. Plizzari, Shear database for reinforced and prestressed beams made with fiber reinforced concrete, in: Proc. 8th Int. Conf. Fract. Mech. Concr. Concr. Struct. Fram, 2013, pp. 1089-1100.

[35] A. Yazdanbakhsh, S. Altoubat, K.-A. Rieder, Analytical study on shear strength of macro synthetic fiber reinforced concrete beams, Eng. Struct. 100 (2015) 622-632, https://doi.org/10.1016/j.engstruct.2015.06.034.

[36] G. Arslan, M. Ozturk, R. Secer, O. Keskin, Shear behaviour of polypropylene fibre - reinforced-concrete beams without stirrups, 2016.

[37] P. Serna Ros, J.R. Martí-Vargas, M.E. Bossio, R. Zerbino, Creep and residual properties of cracked macro-synthetic fibre reinforced concretes, Mag. Concr. Res. 68 (2015) 197-207.

[38] R. Zerbino, D.H. Monetti, G. Giaccio, Creep behaviour of cracked steel and macro-synthetic fibre reinforced concrete, Mater. Struct. 49 (2016) 3397-3410, https://doi.org/10.1617/s11527-015-0727-y.

[39] A.C.A.T.F.M.G.P.S. Moro, Structural applicability of polypropylene fibres: deep and wide-shallow beams subjected to shear, Spec. Publ., 310 (n.d.).

[40] A. Conforti, F. Minelli, G.A. Plizzari, Shear behaviour of prestressed double tees in self-compacting polypropylene fibre reinforced concrete, Eng. Struct. 146 (2017) 93-104, https://doi.org/10.1016/j.engstruct.2017.05.014.

[41] P. Pujadas, A. Blanco, S.H.P. Cavalaro, A. Aguado, S. Grünewald, K. Blom, J.C. Walraven, Plastic fibres as the only reinforcement for flat suspended slabs: parametric study and design considerations, Constr. Build. Mater. 70 (2014) 88-96, https://doi.org/10.1016/j.conbuildmat.2014.07.091.

[42] G. Tiberti, A. Conforti, G.A. Plizzari, Precast segments under TBM hydraulic jacks: experimental investigation on the local splitting behavior, Tunnelling Underground Space Technol. 50 (2015) 438-450, https://doi.org/10.1016/ j.tust.2015.08.013.

[43] M. Di Prisco, S. Tomba, P. Bonalumi, A. Meda, On the use of macro synthetic fibres in precast tunnel segments, in: Proc. Int. Conf. FIBRE Concr., 2015.

[44] A. Conforti, G. Tiberti, G.A. Plizzari, A. Caratelli, A. Meda, Precast tunnel segments reinforced by macro-synthetic fibers, Tunnelling Underground Space Technol. 63 (2017) 1-11, https://doi.org/10.1016/j.tust.2016.12.005.

[45] J.N. Gregori, F. Ortiz Navas, G.E. Leiva Herdoncia, P. Serna, Cuenca E., Experimental reexamination of classic shear-critical concrete beams tests including fibers, in: Proc. 9th RILEM Int. Symp. Fibre-Reinforced Concr. Vancouver, 2016. 